\title{
Zero reference level for right heart catheterisation
}

\author{
Gabor Kovacs, Alexander Avian, Andrea Olschewski and Horst Olschewski
}

Affiliations: Ludwig Boltzmann Institute for Lung Vascular Research, Graz, and Medical University of Graz, Graz, Austria.

Correspondence: G. Kovacs, Ludwig Boltzmann Institute for Lung Vascular Research, 8010 Graz, Stiftingtalstrasse 24, Austria. E-mail: gabor.kovacsaklinikum-graz.at

ABSTRACT Although in the pulmonary circulation small pressure differences may alter the categorisation of patients, there is no consensus on a standard zero reference level (ZRL). In the supine position, ZRL is mostly set at " $5 \mathrm{~cm}$ below anterior thorax surface", " $1 / 3$ thoracic diameter below anterior thorax surface", "mid-thoracic level" or "10 cm above table level".

We retrospectively assessed the distance of these four ZRLs from computed tomography-derived right and left atrial centre levels and from one another in patients undergoing right heart catheterisation and calculated the respective differences in pressure readings.

We included 196 consecutive patients. The ZRL at " $1 / 3$ thoracic diameter" was most often (98.5\%) level with the right atrium, and the ZRL at "mid-thoracic level" was level with the left atrium (97.4\%), revealing a median (range) pressure difference of $-0.3(-3.0-1.3)$ and $0.2(-2.0-1.3) \mathrm{mmHg}$ from the right and left atrial centre level, respectively. The largest differences $(8.0(2.0-15.4) \mathrm{mmHg})$ were found between the ZRLs " $5 \mathrm{~cm}$ below anterior thorax surface" and " $10 \mathrm{~cm}$ above table level". Accordingly, $59 \%$ versus $80 \%$ of patients would be classified with pulmonary hypertension and $7 \%$ versus $38 \%$ with elevated left heart pressures.

The choice of ZRL strongly influences pulmonary pressure readings and pulmonary hypertension classification. 1/3 thoracic diameter mostly represents the right atrium while the left atrium is best represented by the mid-thoracic level.

@ERSpublications

Choice of pulmonary circulation zero reference level influences classification of pulmonary hypertension http://ow.ly/oZ9lQ

This article has supplementary material available from www.erj.ersjournals.com

Received: March 202013 | Accepted after revision: May 292013 | First published online: June 212013

Conflict of interest: Disclosures can be found alongside the online version of this article at www.erj.ersjournals.com

Copyright @ERS 2013 


\section{Introduction}

Right heart catheterisation is the gold standard for the diagnosis of pulmonary hypertension (PH). It allows the direct assessment of pulmonary arterial pressures (PAP), pulmonary arterial wedge pressure (PAWP) and right atrial pressure (RAP), as well as cardiac output. All these measurements are of great importance for the diagnosis, classification and prognostic assessment of $\mathrm{PH}$ [1]. Diagnostic and therapeutic strategies largely depend on determining whether the mean PAP (mPAP) and PAWP exceed $25 \mathrm{mmHg}$ and $15 \mathrm{mmHg}$, respectively. Although all invasive pressure readings rely on the comparison with a zero reference level (ZRL), there is a lack of standardisation for the ZRL during catheterisation [1, 2]. This may lead to considerable differences in pressure readings [3,4], with each centimetre difference between ZRLs causing a pressure difference of $0.78 \mathrm{mmHg}$. According to the published literature, the ZRL is generally recommended to be set at the level of the right atrium, or at the level of the tricuspid valve, based on the concept of the "hydrostatic indifferent point" representing a location in the circulatory system at which gravitational pressure factors caused by changes in body position do not much affect the pressure measurements [5]. In practice, the most frequently used ZRLs in the supine patient are at $5 \mathrm{~cm}$ below the anterior thorax surface [6], at 1/3 of the thoracic diameter below the anterior thorax surface [7], at the midthoracic level [8] and $10 \mathrm{~cm}$ above table level [9]. Nevertheless, there are also arguments for setting the ZRL at the level of the left atrium, particularly if left heart pressures and the distinction between pre- and postcapillary $\mathrm{PH}$ are the focus of interest. Although it may be argued that some methods may be more suitable for right heart haemodynamics and others for left heart haemodynamics, and that the cardiac anatomy may be changed due to the specific disease, a general consensus on the ZRL would be most important. The goal of this study was to compare the most frequently used ZRLs with the anatomical position of the right and the left atrium, as derived from computed tomography (CT) scans in patients admitted for right heart catheterisation. We found that ZRL has a very important impact on the diagnosis and classification of $\mathrm{PH}$.

\section{Patients and methods}

In this retrospective study, we included all consecutive patients who were referred to our $\mathrm{PH}$ clinic for right heart catheterisation between 2006 and 2011, and also had subsequent chest CT. All examinations were performed at the Medical University of Graz, Graz, Austria by an experienced medical team. CT examinations were performed on a 128 slice CT system (Siemens Solutions, Erlangen, Germany). The CT section including the tricuspid valve and optimised for the right atrium was used for further analysis in each patient. In the CT images, in every patient the distance between the anterior thorax surface above the sternum (the skin above the sternum) and the anterior wall of the right atrium (fig. 1a), the diameter of the right atrium (fig. 1b) and the distance between the table level and the posterior wall of the right atrium (fig. 1c), as well as the distance between the middle of the right atrium and the anterior thorax surface (fig. 1d) and table level (fig. 1e) was measured. The centre of the right atrium was chosen as reference ZRL. The distance of the four most frequently used ZRLs $(5 \mathrm{~cm}$ below the anterior thorax surface; $1 / 3$ thoracic diameter below the anterior thorax surface; mid-thoracic level; $10 \mathrm{~cm}$ above table level) from the reference ZRL and from one another were calculated in each patient. Pressure differences ( $\mathrm{mmHg}$ ) were derived from the measured distances between ZRLs using the following equation: pressure difference $(\mathrm{mmHg})=0.78 \times$ distance $(\mathrm{cm})$. The CT scans were reviewed by two independent reviewers and discrepancies in measurements were decided by consensus.

For the comparison of ZRLs with the anatomical position of the left atrium, the CT section optimised for the left atrium was used in analogy to the method described for the right atrium. The axial localisation of the right and left atrium corresponded in most cases to the insertion of the fourth or fifth rib anteriorly to the body of sternum.

Our centre-specific method of defining the ZRL was the level of the anterior axillary line. According to earlier studies, in most cases this corresponds to a ZRL at $1 / 3$ thoracic diameter [10].

Data are presented as mean \pm SD or as median (range). If the assumption of normally distributed data was met, the measures of $\mathrm{PH}$ and non- $\mathrm{PH}$ patients were compared by two-sided t-test. Otherwise, nonparametric tests (Mann-Whitney U-test) were used. The correlation between thoracic diameter and other parameters was examined by Pearson or Spearman correlation. p-values $<0.05$ were considered significant. For data analysis, SPSS 19.0.0 (SPSS Inc. Chicago, IL, USA, 2011) was used.

\section{Results}

We included 196 consecutive patients ( $n=46$ pulmonary arterial hypertension, $n=19 \mathrm{PH}$ due to left heart disease, $n=33 \mathrm{PH}$ due to lung disease, $n=29$ chronic thromboembolic $\mathrm{PH}, \mathrm{n}=8$ other $\mathrm{PH}$ and $\mathrm{n}=61$ patients without $\mathrm{PH}$ ) in this study (patient characteristics in table 1). The intrathoracic distances, as defined in figure 1 , are represented in table 2 for both the right and left atrium. The right atrium was larger in $\mathrm{PH}$ 


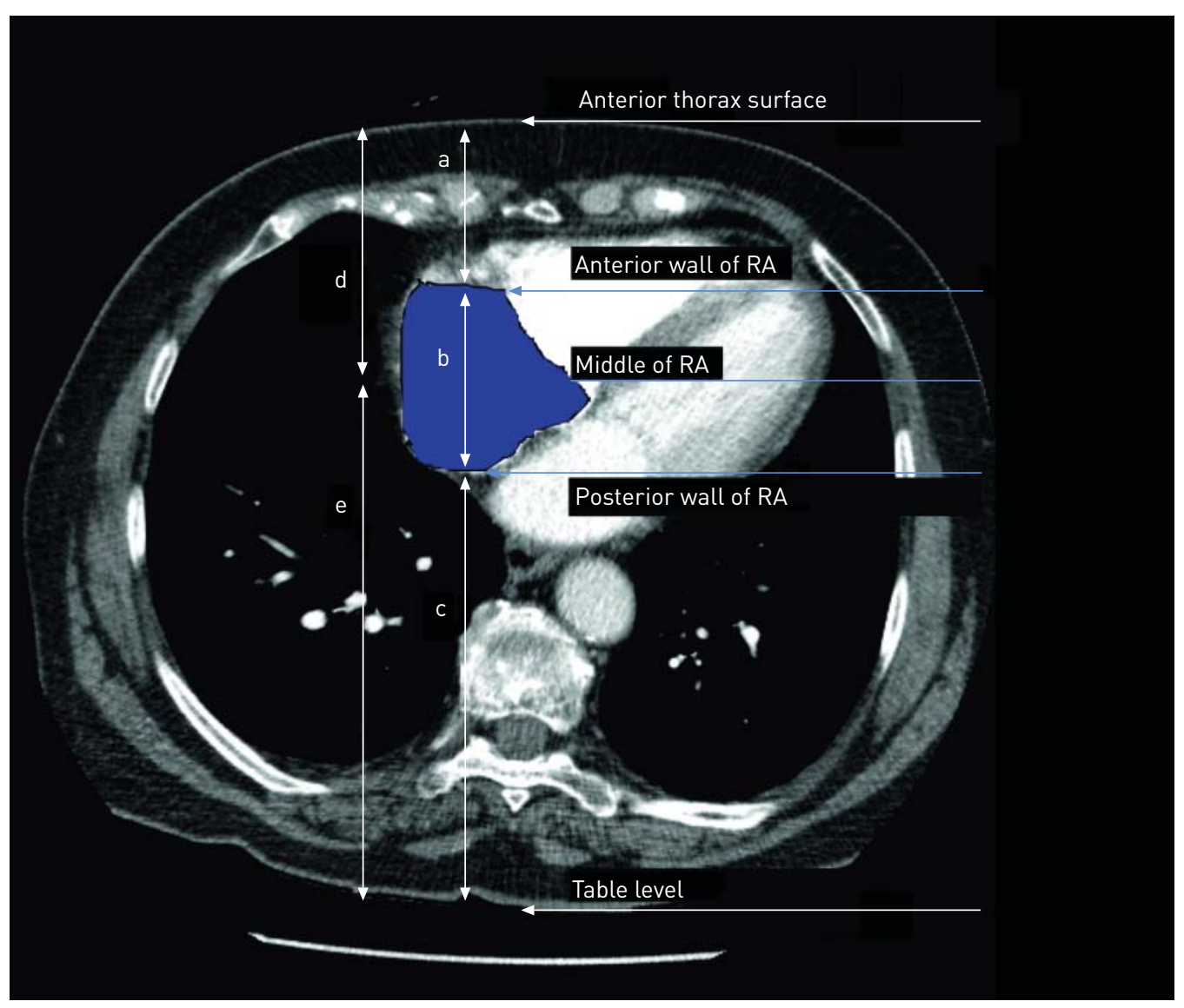

FIGURE 1 Representative computed tomography image showing a) the distance between the anterior skin above sternum and the anterior wall of the right atrium (RA), b) the atrial diameter, c) the distance between the posterior wall of the right atrium and the table level, d) the distance between the anterior skin and the centre of the right atrium and e) the distance between the right atrial centre and the table level.

patients as compared to patients without $\mathrm{PH}$; other intrathoracic measures did not differ significantly among the groups. The thoracic diameter was correlated with body mass index (BMI) $(\mathrm{p}<0.001, \mathrm{r}=0.69)$, but showed no significant correlation with age $(\mathrm{p}=0.095, \mathrm{r}=0.12)$ or forced expiratory volume in $1 \mathrm{~s}$ $(\mathrm{p}=0.188, \mathrm{r}=-0.10)$.

Out of the four ZRLs analysed, the one at " $1 / 3$ thoracic diameter below anterior thorax surface" was localised in $98.5 \%$ of patients between the anterior and posterior wall of the right atrium while the ZRL at "10 cm above table level" was only in $3.6 \%$ of cases at this level (table 3, fig. 2). The deviation of the analysed four ZRLs from the centre of the right atrium and the pressure differences employing these ZRLs as compared to the centre of the right atrium are represented in table 3 and in supplementary figure S1. Accordingly, the ZRL shift from the mid-atrial level to an alternative ZRL would have changed the classification of $\mathrm{PH}$ in $9 \%$ (" $5 \mathrm{~cm}$ below the anterior thorax surface"), $0 \%$ (" $1 / 3$ thoracic diameter below anterior thorax surface"), $8 \%$ ("mid-thoracic level") and $12 \%$ ("10 cm above table level") of patients (table 4). In addition, such a shift would have led to a relevant change in the PAWP classification (below or above $15 \mathrm{mmHg}$ ) in $5 \%, 2 \%, 10 \%$ and $26 \%$ of patients, respectively (table 4 ).

Regarding the left atrium, the best approximation was reached by the mid-thoracic level (tables 4 and 5, fig. 3), revealing a pressure difference of only $0.2(-2.0-1.3) \mathrm{mmHg}$ as compared to the left atrial centre level.

When the four analysed ZRLs were compared to one another, the median differences ranged between 2.1 and $8.0 \mathrm{mmHg}$ (table 6). In an obese patient, this difference was as much as $15.4 \mathrm{mmHg}$. Due to these differences, the switch from ZRL " $5 \mathrm{~cm}$ below the anterior thorax surface" to ZRL " $10 \mathrm{~cm}$ above table level" would have led to a change in $\mathrm{PH}$ diagnosis in $21 \%$ of cases, and to a change in the PAWP class in $31 \%$ of cases (table 4 ). 


\begin{tabular}{|c|c|c|c|c|}
\hline & All patients & PH patients & Non-PH patients & p-value \\
\hline Females/males $\mathrm{n} / \mathrm{n}$ & $114 / 82$ & $74 / 61$ & $40 / 21$ & 0.157 \\
\hline Age yrs & $63 \pm 14$ & $64 \pm 14$ & $59 \pm 13$ & 0.001 \\
\hline Weight kg & $76 \pm 17$ & $76 \pm 18$ & $74 \pm 15$ & 0.524 \\
\hline Body mass index $\mathrm{kg} \cdot \mathrm{m}^{-2}$ & $27.0 \pm 5.8$ & $27.1 \pm 6.0$ & $26.6 \pm 5.3$ & 0.667 \\
\hline Body surface area $\mathrm{m}^{2}$ & $1.8 \pm 0.2$ & $1.8 \pm 0.2$ & $1.8 \pm 0.2$ & 0.671 \\
\hline Pulmonary vascular resistance dyn $\cdot \mathrm{s} \cdot \mathrm{cm}^{-5}$ & $437 \pm 322$ & $560 \pm 316$ & $165 \pm 72$ & $<0.001$ \\
\hline FEV1 \% pred & $71 \pm 23$ & $68 \pm 23$ & $79 \pm 19$ & 0.001 \\
\hline FEV1/FVC \% & $75 \pm 12$ & $73 \pm 13$ & $77 \pm 11$ & 0.029 \\
\hline
\end{tabular}

Data are presented as mean \pm SD, unless otherwise stated. PH: pulmonary hypertension; FEV1: forced expiratory volume in 1 s; FVC: forced vital capacity. Bold indicates statistical significance.

\begin{abstract}
Discussion
In this retrospective study we analysed four different commonly used ZRLs in patients with $\mathrm{PH}$ in the supine position. We found that there were relevant differences among these methods, leading to clinically significant differences in the readings of intrathoracic blood pressures. According to our study, the ZRL set to $1 / 3$ of the thoracic diameter below the anterior thorax surface (below the skin above the sternum) would favourably correspond to a ZRL within the right atrium in most patients, while the other commonly used ZRLs would cause significant differences from this reference level. The centre of the left atrium was best described by the "mid-thoracic level", providing an easily reproducible ZRL, which may be particularly relevant for the assessment of PAWP. According to the normal axial location of the right and left atrium, the insertion of the fourth or fifth rib anteriorly to the body of sternum would be an appropriate axial level for the setting of ZRL in the supine position.
\end{abstract}

Where is the ideal ZRL?

Every pressure reading during a catheter investigation is a difference between the pressure at the chosen ZRL and in the "chamber or vessel" where the fluid-filled catheter tip is located, provided there is no obstruction and no significant flow within the catheter. According to one classical physiological theory going back to the

TABLE 2 Intrathoracic measures of patients

All patients PH patients $\begin{aligned} & \text { Non-PH } \\ & \text { patients }\end{aligned}$

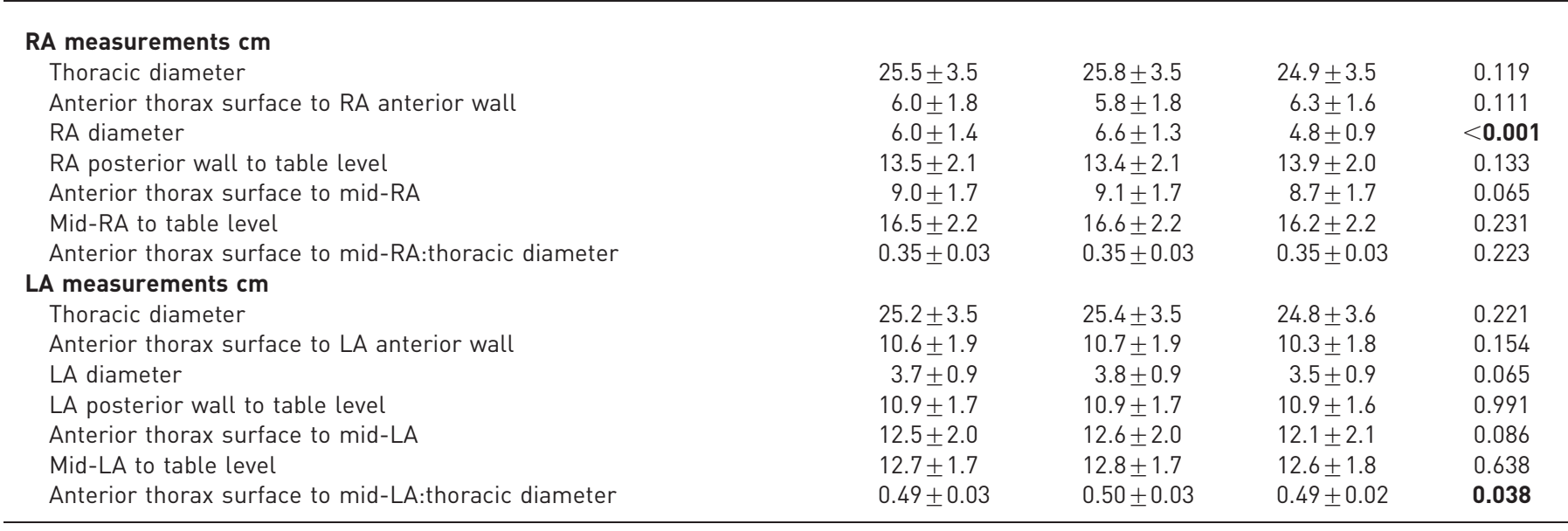

Measures derived from thoracic computed tomography scan, as outlined in figure 1. PH: pulmonary hypertension; RA: right atrium; LA: left atrium. Bold indicates statistical significance. 
TABLE 3 Distance and calculated pressure differences of zero reference levels (ZRLs) from the centre of the right atrium (RA) and the frequency of ZRLs being at the level of the RA

\section{Distance from mid-RA level cm}

Pressure difference compared to mid-RA level $\mathrm{mmHg}$
Patients with ZRL at the level of the RA

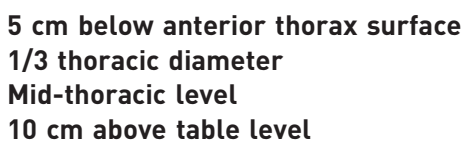

$-3.0(-8.0--0.4)$
$-0.3(-3.0-1.3)$
$3.0(1.3-4.9)$
$5.0(0.7-9.4)$

$57 / 196(29.1 \%)$

$193 / 196(98.5 \%)$

$49 / 196(25.0 \%)$

$7 / 196(3.6 \%)$

Data are presented as median (range), unless otherwise stated.

end of the 19th century [11], the ZRL should be set at the level of the "physiologic zero point" or "hydrostatic indifferent point" which represents the location in the cardiovascular system where the central venous pressure is tightly regulated, changing little if at all during the volume shifts caused by changes in the position $[12,13]$. This point may be found at the junction of "phlebostatic levels" [14] and was supposed to be within the right atrium or in the right ventricle next to the tricuspid valve, but in any case at the level of the right atrium in the supine patient. Accordingly, it has been widely accepted that in the case of PAP and venous pressure measurements, the ideal ZRL should be set at the level of the right atrium [6, 9, 15-17]. However, in the search for the optimal ZRL, it may also be adequate to refer to the level of the left atrium $[18,19]$, particularly if the diastolic function of the left ventricle is to be analysed.

\section{How to define the level of the right atrium?}

There were several efforts to define well recognisable external points which may help to set the ZRL at the level of the right atrium in the supine position. However, there is considerable heterogeneity among the methods, which may be classified into the following approaches: 1) fixed distance from the anterior surface of the chest; 2) fixed distance from the table level; 3) a measure relative to the anterio-posterior diameter of the chest; and 4) individual determination by echocardiography or other imaging technique.

The first method was suggested by MORITZ and VON TABORA [6] on the basis of cadaver examinations, and has the advantage of being easy to perform, well reproducible and insensitive to softer underlayment. According to most studies, the ZRL was set at $5 \mathrm{~cm}$ below the surface of the thorax. The method was mainly criticised because in individuals with large thoracic diameters this ZRL may be too high, resulting in too low pressure readings [9].

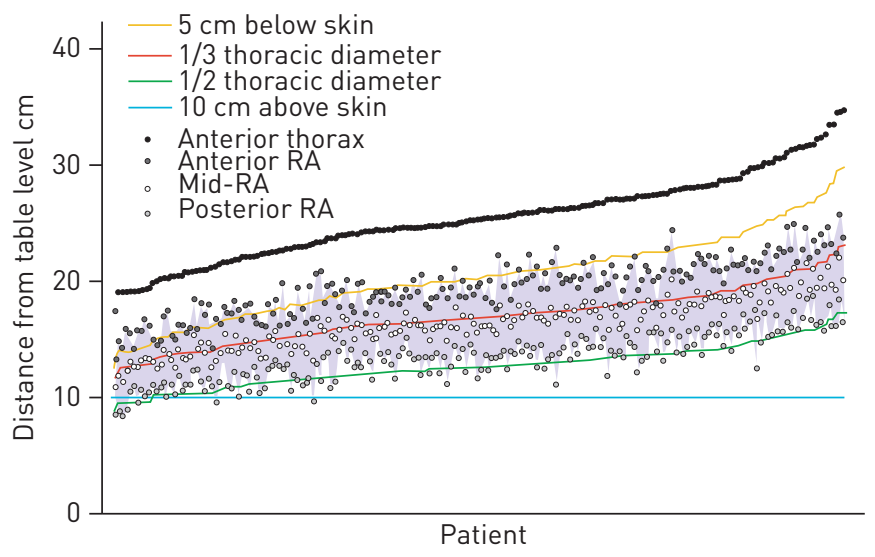

FIGURE 2 Distance of the right atrium from table level. All 196 patients were sorted on the $x$-axis according to their thoracic diameter in the computed tomography slice optimised for the right atrium (RA). The anterior and posterior walls of the right atrium and the right atrial centre of each patient are given. The blue area represents the distance between the anterior and posterior right atrial wall. Coloured lines represent different zero reference level (ZRL) definitions. It can be seen that the ZRL at $1 / 3$ thoracic diameter is near to the centre of the right atrium in most patients, whereas the ZRL at $5 \mathrm{~cm}$ below thoracic surface is around the anterior wall of the right atrium, the ZRL at the mid-thoracic line is mainly around the posterior wall of the right atrium. The ZRL at $10 \mathrm{~cm}$ above table level is in most cases below the level of both. 
TABLE 4 Percentage of patients $(\mathrm{n}=196)$ with mean pulmonary arterial pressure (mPAP) $\geqslant 25 \mathrm{mmHg}$ versus $<25 \mathrm{mmHg}$ and with pulmonary arterial wedge pressure (PAWP) $>15 \mathrm{mmHg}$ versus $\leqslant 15 \mathrm{mmHg}$ depending on the chosen zero reference level

mPAP $\geqslant 25 \mathrm{mmHg} \% \quad \operatorname{mPAP}<25 \mathrm{mmHg} \% \quad$ PAWP $>15 \mathrm{mmHg} \% \quad$ PAWP $\leqslant 15 \mathrm{mmHg} \%$

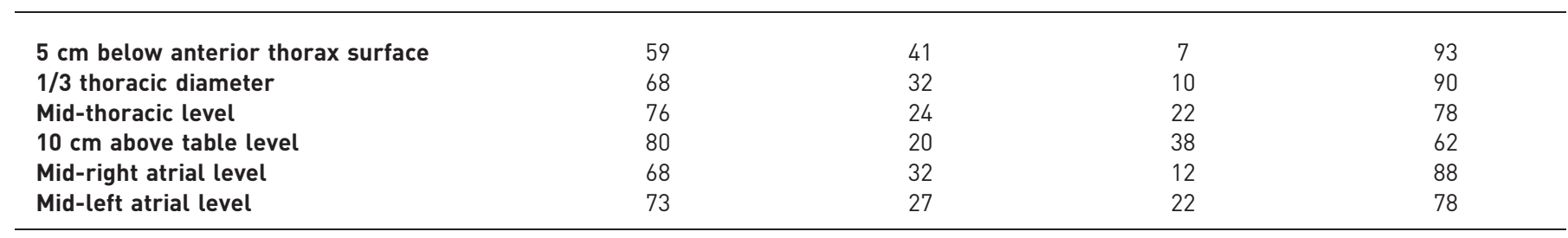

According to the second approach, the ZRL is mostly set at $10 \mathrm{~cm}$ from the table level. This approach was also based on cadaver examinations and suggested by LYons et al. [9]. Based on their measurements, normal subjects had the smallest variability by using this approach. The method is widely accepted, easy to perform, but has also been criticised by several authors $[10,20]$ and comparison studies. The main argument against this method was that in patients with large thoracic diameters the ZRL may be below the level of the heart.

The third approach provides a measure relative to the anterio-posterior diameter of the chest. Several options have been suggested, but most frequently the mid-chest level $[8,18]$, the $1 / 3$ to $2 / 3$ ratio of the thoracic diameter [7, 21, 22], the mid-axillary line [23-25] and the anterior axillary line [26, 27] were used. Comparison studies found these approaches to provide more accurate ZRLs as compared to fixed distances from the anterior thorax surface or the spine [10]. One disadvantage is that the determination of the ZRL is more difficult and may lead to errors and considerable variability, when the method is applied by different and/or inexperienced personal [28].

A fourth method was suggested by COURTOIs et al. [29], based upon individual determination of the ZRL by echocardiography. Although the use of the ultrasound approach may appear complex for everyday routine, it might enhance diagnostic accuracy in centres that use the readings for scientific reasons.

In this retrospective study, we used CT images in order to define the true level of the right atrium. This allowed for an unequivocal determination of the centre of the right and left atrium in every single patient. We consider both as possible reference ZRLs. ZRL methods that employed the antero-posterior thoracic diameter appeared to be more accurate as compared to ZRLs with a fixed distance from either the anterior body surface or the table level. The best agreement with the right atrium was found, both in patients with and without $\mathrm{PH}$, when the ZRL " $1 / 3$ thoracic diameter below anterior thorax surface" was used, while the $\mathrm{ZRL}$ at $10 \mathrm{~cm}$ above table level quite poorly predicted the right atrial level. This may be due to the fact that we generally found larger thoracic diameters in our patients compared to most historic cohorts. As thoracic diameter was correlated with BMI, this may be explained by the increase of BMI in the population during the past decades. It may be mentioned that, in the REVEAL registry, the BMI of PH patients was even higher than in our cohort [30]; therefore, the impact of ZRL definition would have even been larger than in our study. For the left atrial level, the mid-thoracic line was most adequate in nearly all our patients. This suggests that, for scientific questions related to left ventricular function, the ZRL at the mid-thoracic level might be ideal.

TABLE 5 Distance and calculated pressure differences of zero reference levels (ZRLs) from the centre of the left atrium (LA) and the frequency of ZRLs being at the level of the LA

\section{Distance from mid-LA} level $\mathrm{cm}$
Pressure difference compared to mid-LA level $\mathrm{mmHg}$
Patients with ZRL at the level of the LA

\begin{tabular}{lccc}
\hline $\mathbf{5} \mathbf{~ c m}$ below anterior thorax surface & $-7.4(-14.6--3.3)$ & $-5.8(-11.4--2.6)$ & $0 / 196(0 \%)$ \\
$\mathbf{1} \mathbf{3}$ thoracic diameter & $-4.1(-8.2--2.0)$ & $-3.2(-6.4--1.6)$ & $0 / 196(0 \%)$ \\
Mid-thoracic level & $0.2(-2.5-1.7)$ & $0.2(-2.0-1.3)$ & $191 / 196(97.4 \%)$ \\
$\mathbf{1 0} \mathbf{~ c m}$ above table level & $2.7(-1.5-7.0)$ & $2.1(-1.2-5.5)$ & $61 / 196(31.1 \%)$ \\
\hline
\end{tabular}

Data are presented as median (range), unless otherwise stated. 


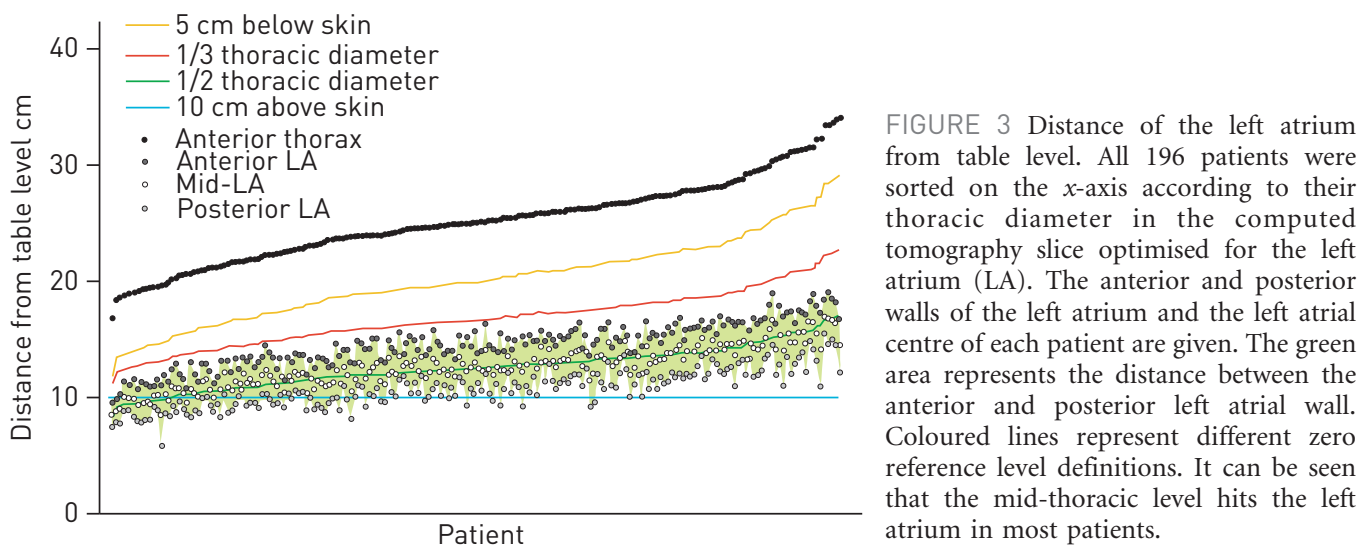

\section{Clinical relevance}

How do differences between ZRLs lead to pressure differences? As the specific gravities for blood and mercury are 1.055 and 13.6, a blood column of $1 \mathrm{~cm}$ is equivalent to a mercury column of $0.78 \mathrm{~mm}$. Accordingly, by shifting the ZRL from the mid-atrial ZRL to " $5 \mathrm{~cm}$ below anterior thorax surface", the percentage of patients in our patient cohort with mean PAP $\geqslant 25 \mathrm{mmHg}$ would decrease from $68 \%$ to $59 \%$, while shifting the ZRL to the level " $10 \mathrm{~cm}$ above table level" would increase this percentage to $80 \%$ (table 4). Similar changes may be observed regarding PAWP. PAWP readings are of special relevance for the diagnosis of pulmonary arterial hypertension, because readings $>15 \mathrm{mmHg}$ preclude this diagnosis [1]. Notably, in their description of left atrial pressures in normal subjects, BRAUNWALD and co-workers set the $\mathrm{ZRL}$ at $5 \mathrm{~cm}$ below the anterior thorax surface and found that the normal left atrial pressure never exceeded $12 \mathrm{mmHg}[31,32]$. However, other ZRLs, such as $10 \mathrm{~cm}$ above table level, would have resulted in significantly higher values [33]. Therefore, one of the major confounding factors for any definition of the "normal range of PAWP" is the definition of ZRL. This may be of special interest when the upper limit of PAWP is considered among the inclusion criteria of PAH studies, as the $15 \mathrm{mmHg}$ cut-off value using the 1/3-thoracic diameter ZRL would be very close to the $12 \mathrm{mmHg}$ cut-off level described by BRAUNWALD et al. [31] using the ZRL $5 \mathrm{~cm}$ below the sternal angle.

Unfortunately, in different countries, different cities, and even within centres, different ZRL methods have been used and there is no consensus on a gold standard. This may lead to therapeutic consequences for patients, particularly in the obese population. Therefore, a uniform definition of ZRL should be established, in order to avoid discrepancies and misconceptions about the definitions of $\mathrm{PH}$ and elevated left heart pressures. Remarkably, independent of BMI and thoracic diameter, the reference line at $1 / 3$ thoracic diameter remained representative for the right atrium and the one at $1 / 2$ thoracic diameter for the left atrium in our study. When choosing the appropriate ZRL, besides physiological considerations, also the practicability and reproducibility of the method has to be taken into account [28]. This might speak in favour of the mid-thoracic level.

\section{Limitations}

In this manuscript, we focused on the influence of ZRL on pressure readings in the supine position. We did not address other important issues such as the role of in- and expiration [34], intrathoracic pressure and its changes caused by obstructive or restrictive lung diseases and by exercise. In addition, we did not address the question, where the ZRL should be placed in the upright or semi-upright positions. Based on the "phlebostatic axis" theory, in the sitting position, the use of the fourth intercostal space for ZRL may be the

TABLE 6 Pressure differences between zero reference levels

$5 \mathrm{~cm}$ below anterior thorax

$1 / 3$ thoracic diameter

Midthoracic level surface

$\begin{array}{ll}1 / 3 \text { thoracic diameter } & 2.7(0.6-5.1) \\ \text { midthoracic level } & 6.0(2.9-9.6) \\ 10 \mathrm{~cm} \text { above table level } & 8.0(2.0-15.4)\end{array}$

$5.4(1.3-10.2)$

$2.1(-1.0-5.7)$

Data are presented as median (range). 
most widespread one [14]. We feel that all these mentioned factors are very important for the interpretation of pressure readings, but they cannot be addressed adequately, if there is no consensus on the ZRL in the supine position.

Our chest CT readings may have included the vena cava confluens as part of the right atrium in some patients, leading to a slight overestimation of right atrial diameters. This may have influenced the localisation of the posterior wall of the right atrium, causing a minor error in the determination of the centre of the right atrium.

The choice of the CT slice for the thoracic diameter measurement was based on the optimal presentation of the right or left atrium in the chest CT, and not on an anatomical landmark. The detected diameters showed only minimal differences $(0.3 \pm 0.5 \mathrm{~cm})$ between these two slices. Therefore, in the absence of major thoracic deformities, a significant effect of these differences appears unlikely.

The proportion of patients with changes in final diagnosis due to the change of ZRL is dependent on the examined population. This rate may have been different in a centre, where more patients with congestive heart failure or less patients with slightly elevated PAP values would have been investigated than in our study. This, however, does not question the necessity of standardisation.

\section{Conclusion}

The four most commonly used methods for ZRL setting result in significantly different thoracic blood pressure readings and may significantly influence the classification of $\mathrm{PH}$ patients. As long as there is no international standard, the method of zeroing should be provided in each study on haemodynamics.

\section{Acknowledgement}

We would like to thank to Robert Naeije (Erasme University Hospital, Brussels, Belgium) for the fruitful discussions on this topic.

\section{References}

1 Galie N, Hoeper MM, Humbert M, et al. Guidelines for the diagnosis and treatment of pulmonary hypertension. Eur Respir J 2009; 34: 1219-1263.

Pulmonary Artery Catheter Consensus conference: consensus statement. Crit Care Med 1997; 25: 910-925.

3 Fishman A. Dynamics of the Pulmonary Circulation. In: Hamilton W, Dow P, eds. Handbook of Physiology. Washington, American Physiological Society, 1963; pp. 1667-1743.

4 Wood P. Diseases of the Heart and Circulation. London, Eyre and Spottiswoode, 1968.

5 Guyton AC, Hall JE. Vascular Distensibility and Functions of the Arterial and Venous Systems. In: Guyton AC, Hall JE, eds. Textbook of Medical Physiology. 11th Edn. Oxford, Elsevier, 2005; pp. 171-180.

6 Moritz F, von Tabora D. Über eine Methode, beim Menschen den Druck in oberflächlichen Venen exakt zu bestimmen [A method for determining exact superficial venous pressure in humans]. Deutsches Archiv für klinische Medizin 1910; 98: 475-505.

$7 \quad$ Eyster JAE, ed. The Clinical Aspects of Venous Pressure. New York, Macmillan, 1929.

8 von Recklinghausen H. Unblutige Blutdruckmessung [Noninvasive blood pressure measurement]. Archiv für experimentelle Pathologie und Pharmakologie 1906; 55: 463-504.

9 Lyons R, Kennedy A, Burwell S. The measurement of venous pressure by the direct method. Am Heart J 1938; 16: 675-693.

10 Pederson A, Husby J. Venous pressure measurement. Acta Med Scand 1951; 141: 185-194.

11 Hill L. The influence of the force of gravity on the circulation of the blood. J Physiol 1895; 18: 15-53.

12 Guyton AC, Greganti FP. A physiologic reference point for measuring circulatory pressures in the dog; particularly venous pressure. Am J Physiol 1956; 185: 137-141.

13 McGee SR. Physical examination of venous pressure: a critical review. Am Heart J 1998; 136: 10-18.

14 Winsor T, Burch G. Phlebostatic axis and phlebostatic level: reference levels for venous pressure measurements in man. Proc Soc Exp Biol Med 1945; 58: 165-169.

15 Frey A. Über die Bedeutung der Venendruckmessung bei der diätetisch-physikalischen Behandlung der Kreislaufstörungen [The relevance of venous pressure measurement at the dietary and physical treatment of circulatory disorders]. Deutsches Archiv für klinische Medizin 1902; 73: 511-545.

16 Kee LL, Simonson JS, Stotts NA, et al. Echocardiographic determination of valid zero reference levels in supine and lateral positions. Am J Crit Care 1993; 2: 72-80.

17 Holt JP. The measurement of venous pressure in man eliminating the hydrostatic factor. Am J Physiol 1940; 130: 635-641.

18 Paolella LP, Dorfman GS, Cronan JJ, et al. Topographic location of the left atrium by computed tomography: reducing pulmonary artery catheter calibration error. Crit Care Med 1988; 16: 1154-1156.

19 Seo JH, Jung CW, Bahk JH. Uppermost blood levels of the right and left atria in the supine position: implication for measuring central venous pressure and pulmonary artery wedge pressure. Anesthesiology 2007; 107: 260-263.

20 Debrunner F, Buhler F. "Normal central venous pressure," significance of reference point and normal range. $\mathrm{Br}$ Med J 1969; 3: 148-150.

21 Richards DWJ, Cournand A, Darling RC, et al. Pressure in the right auricle of man, in normal subjects and in patients with congestive heart failure. Tr A Am Physicians 1941; 56: 218-221.

22 Brams W, Katz L, Schutz W. Intravenous Pressure: I. New Method of Determination. Arch Intern Med 1933; 51: 33-37. 
23 Mueller HS, Chatterjee K, Davis BK, et al. Present use of bedside right heart catherization in patients with cardiac disease. J Am Coll Cardiol 1998; 32: 840-864.

24 Wartmann WB. A study of the venous blood pressure in some common diseases. Am J Med Sci 1935: 464-477.

25 Evans W. Venous pressure. N Engl J Med 1932; 207: 934-940.

26 Gaertner G. Die Messung des Drucks im rechten Vorhof [Measurement of right atrial pressure]. Münchener medizinische Wochenschrift 1903; 50: 2038-2041.

27 Harris I. Venous pressure in heart disease. Edinburgh Med J 1928; 35: 630-650.

28 Drake JJ. Locating the external reference point for central venous pressure determination. Nurs Res 1974; 23: 475-482.

29 Courtois M, Fattal PG, Kovacs SJ Jr, et al. Anatomically and physiologically based reference level for measurement of intracardiac pressures. Circulation 1995; 92: 1994-2000.

30 Frost AE, Badesch DB, Barst RJ, et al. The changing picture of patients with pulmonary arterial hypertension in the United States: how REVEAL differs from historic and non-US Contemporary Registries. Chest 2011; 139: 128-137.

31 Braunwald E, Brockenbrough EC, Frahm CJ, et al. Left atrial and left ventricular pressures in subjects without cardiovascular disease: observations in eighteen patients studied by transseptal left heart catheterization. Circulation 1961; 24: 267-269.

32 Bonow R, Mann D, Zipes D, et al., eds. Braunwald's Heart Disease: A Textbook of Cardiovascular Medicine. Philadelphia, Elsevier, 2012.

33 Chandraratna PA. Determination of zero reference level for left atrial pressure by echocardiography. Am Heart J 1975; 89: 159-162.

34 Ryan JJ, Rich JD, Thiruvoipati T, et al. Current practice for determining pulmonary capillary wedge pressure predisposes to serious errors in the classification of patients with pulmonary hypertension. Am Heart J 2012; 163: 589-594. 